\title{
No child is an island: sociability in times of social distancing
}

\author{
Melchior Maria ${ }^{1}$
}

Published online: 12 June 2020

(c) Springer-Verlag GmbH Germany, part of Springer Nature 2020

The worldwide COVID-19 pandemic and the implementation of so-called 'social distancing' measures to slow it down remind us that, as Aristotle wrote, 'humans are social animals'. Thus avoidance of social contacts with others is generally unnatural or a sign of difficulty. Children's ties with their primary caretakers and other members of the family are the stepping stone to develop lifelong social competencies and skills. But as they grow older and particularly in adolescence, social relations with adults outside the family, and most importantly with peers, become key. Nurseries and schools, as well as parks and leisure activities when children meet and interact offer essential contexts for youth development, and their closure has no doubt had an impact on children and adolescents' quality of life and well-being [1].

Although written well before the COVID-19 epidemic began, articles in this month's issue of European Child and Adolescent Psychiatry highlight the importance of different types of sociability and the quality of ties with others with regard to children's development.

The article by Bennett et al. [2], shows that the experience of social isolation in childhood predicts the occurrence of psychotic symptoms in adulthood, among approximately 1200 persons followed over twenty years. These data are consistent with prior reports of social exclusion co-occurring with psychotic experiences [3]. While social isolation has been described as the most frequent co-occurring factor in early cases of psychosis, especially in families where both children and parents are affected [4], in this community sample childhood psychosis is quite unlikely. It is more probable that in this case social exclusion is a direct risk factor of psychological suffering or an early risk marker of relationship difficulties, which can lead to later psychiatric disorder. Importantly, recent research highlights the distinction between social isolation (absence of or few significant

Melchior Maria

maria.melchior@inserm.fr

1 INSERM Sorbonne Université, IPLESP UMRS 1136, Paris, France social ties-ie contacts with family, friends, and low participation in formal social groups such as clubs, associations, religious networks) and loneliness, characterized by the feeling of being alone and lacking social support regardless the number of persons within one's social network. Importantly, loneliness is considered to be a source of pain and suffering and may activate the same brain regions as physical pain [5]. Loneliness, thought to affect $15-30 \%$ of adults in the general population, often originates in childhood, and although its determinants are not yet fully understood, they probably include a combination of innate and environmental factors [6]. One of the known risk factors of loneliness among young people is the presence of anxiety disorders, which should be screened for and treated to improve young people's social as well as health outcomes [7-9].

Of course an especially important environment where children and adolescents establish social ties with others is school. The letter by Heyne et al. [10], on behalf of the International Network for School Attendance (INSA) highlights the critical role of promoting youth's school attendance in order to favor their social and psychological well-being, and points to a number of difficulties that emerge in doing so. First, educational systems being extremely varied, there are no standardized benchmarks of school attendance, i.e. cut-offs which parents, teachers, and health professionals should consider to evaluate whether there is a problem or to evaluate whether interventions aimed at promoting school attendance are efficacious. Second, key 'stakeholders'-i.e. adolescents, their parents and educational staff, as well as child and adolescent psychiatrists need to be included in efforts to promote school attendance, which is often complex to achieve in the absence of established networks. To be health-promoting, school settings need to explicitly promote students' psychosocial and coping skills, resilience in face of stress as well as socialization [11, 12]. As shown by recent data collected among school-aged children and adolescents across Europe, stress and emotional distress levels among European youth are on the increase, suggesting that efforts to support youths to prevent social isolation and distress should 
be more pronounced than ever, and schools are an important setting for these types of interventions [13].

The COVID-19 pandemic and social distancing measures that accompany it are likely not only to disturb normal life, but also to result in a severe economic crisis in Europe and other parts of the world. As is often the case, this economic crisis will probably take a greater toll on populations that are vulnerable, such as families with young children-particularly those that are headed by a single parent. Hence, helping children build up resilience by encouraging them to develop strong social ties, identifying and treating early those who have psychological difficulties that impede their social skills, and investing collectively in school environments that are safe and health promoting, will be more of a priority than ever in upcoming months.

\section{References}

1. Clemens V, Deschamps P, Fegert JM, Anagnostopoulos D, Bailey S, Doyle M et al (2020) Potential effects of "social" distancing measures and school lockdown on child and adolescent mental health. Eur Child Adolesc Psychiatry. https://doi.org/10.1007/ s00787-020-01549-w

2. Bennett JC, Surkan PJ, Moulton LH, Fombonne E, Melchior M (2019) Childhood social isolation and psychotic experiences in young adulthood: a community based study. Eur Child Adolesc Psychiatry. https://doi.org/10.1007/s00787-019-01417-2

3. el Bouhaddani S, van Domburgh L, Schaefer B, Doreleijers TAH, Veling W (2018) Peer status in relation to psychotic experiences and psychosocial problems in adolescents: a longitudinal schoolbased study. Eur Child Adolesc Psychiatry 27(6):701-710

4. Vigo L, Ilzarbe D, Baeza I, Banerjea P, Kyriakopoulos M (2019) Shared psychotic disorder in children and young people: a systematic review. Eur Child Adolesc Psychiatry 28(12):1555-1566

5. Matthews T, Danese A, Wertz J, Odgers CL, Ambler A, Moffitt TE et al (2016) Social isolation, loneliness and depression in young adulthood: a behavioural genetic analysis. Soc Psychiatry Psychiatr Epidemiol 51(3):339-348
6. Hawkley LC, Cacioppo JT (2010) Loneliness matters: a theoretical and empirical review of consequences and mechanisms. Ann Behav Med 40(2):218-227

7. de Lijster JM, Dieleman GC, Utens EMWJ, Dierckx B, Wierenga M, Verhulst FC et al (2018) Social and academic functioning in adolescents with anxiety disorders: a systematic review. J Affect Disord 230:108-117

8. Golombek K, Lidle L, Tuschen-Caffier B, Schmitz J, Vierrath V (2019) The role of emotion regulation in socially anxious children and adolescents: a systematic review. Eur Child Adolesc Psychiatry. https://doi.org/10.1007/s00787-019-01359-9

9. Knollmann M, Reissner V, Hebebrand J (2019) Towards a comprehensive assessment of school absenteeism: development and initial validation of the inventory of school attendance problems. Eur Child Adolesc Psychiatry mars 28(3):399-414

10. Heyne D, Gentle-Genitty C, Gren Landell M, Melvin G, Chu B, Gallé-Tessonneau M et al (2019) Improving school attendance by enhancing communication among stakeholders: establishment of the International Network for School Attendance (INSA). Eur Child Adolesc Psychiatry. https://doi.org/10.1007/s00787-01901380-y

11. Kahn J-P, Cohen RF, Tubiana A, Legrand K, Wasserman C, Carli $V$ et al (2020) Influence of coping strategies on the efficacy of YAM (Youth Aware of Mental Health): a universal school-based suicide preventive program. Eur Child Adolesc Psychiatry. https ://doi.org/10.1007/s00787-020-01476-w

12. Las Hayas C, Izco-Basurko I, Fullaondo A, Gabrielli S, Zwiefka A, Hjemdal O et al (2019) UPRIGHT, a resilience-based intervention to promote mental well-being in schools: study rationale and methodology for a European randomized controlled trial. BMC Public Health 19(1):1413

13. Inchley J, Currie D, Budisavljevic S, Torsheim T, Jåstad A, Cosma A, et al. Spotlight on adolescent health and well-being. Findings from the 2017/2018 Health Behaviour in School-aged Children (HBSC) survey in Europe and Canada. International report. Volume 1. Key findings. [Internet]. Copenhagen: WHO Regional Office for Europe; 2020. Disponible sur: https://www.euro.who. int/en/health-topics/Life-stages/child-and-adolescent-health/healt h-behaviour-in-school-aged-children-hbsc/publications/2020/ spotlight-on-adolescent-health-and-well-being.-findings-fromthe-20172018-health-behaviour-in-school-aged-children-hbscsurvey-in-europe-and-canada.-international-report.-volume-1.key-findings. Accessed 1 June 2020 